\title{
France puts big science under scrutiny
}

[PARIS] France is to re-evaluate its commitments to international 'big-science' projects and its own national research facilities.

Officials at the science ministry decline to give specific examples of which such projects might be targets for cuts. But the move may raise questions over the terms of France's participation in facilities such as the planned international space station and the European Laboratory for Particle Physics (CERN).

The new socialist government also plans a radical reform of its national research agencies, and the way they evaluate laboratories and grant applications. It will substantially increase the recruitment of scientists, and will create a system of short-term postdoctoral fellowships in a country where lifetime employment has been the rule.

Government sources say that Claude Allègre, the minister of national education, research and technology, is deeply sceptical of the value of many big-science facilities, believing they often escape proper evaluation.

According to one ministry official, the prowess of powerful scientific lobbies has often been the main factor in persuading politicians of the case for constructing bigger and better machines. Proposals for new national facilities will be considered only if the possibility of international funding has been "extensively" explored, he adds.

\section{Ocean drilling}

Big science is one area where the cashstrapped government feels it can make savings, says the official, adding that both national facilities and France's international commitments will be reviewed.

One project likely to come under close scrutiny is the international Ocean Drilling Program, whose value for money has already been questioned (see Nature 379, 193; 1996). Allègre, an Earth scientist by background, is also known to be sceptical of the usefulness of manned space flight, including the planned international space station.

The government's hands are tied to some extent by the fact that responsibility for space policy is shared with the president, Jacques Chirac. But the government intends to appoint a new director-general of the French space agency CNES, for which Allègre is responsible, to reorientate the agency's activities. Support for CNES has previously been motivated by national prestige. "CNES in the future will be driven far more by technical and scientific aspects," says the official.

Allègre last week gave his first press conference since becoming minister. He confirmed his intention to end staff cuts throughout the research and education systems, and to create "hundreds" of new posts for researchers, technicians and lecturers within the research organizations and universities by as early as September. This would be followed by sustained high levels of recruitment to offset the scheduled massive wave of retirement over the next decade.

The science ministry has some margin to allow it to make such new investments. Lionel Jospin, the prime minister, has confirmed that research and education will be national priorities and that this will be one of the few ministries to receive increased funding in the September budget. But Vincent Courtillot, Allègre's principal adviser, says the increase will be "significant but not overwhelming".

Massive increases in public spending have been ruled out as a result of the government's obligation to meet the budgetary criteria for joining the single European currency, and some financial acrobatics will be needed. Allègre hopes to finance increases for his main goals, for example, by making cuts and economies elsewhere within his existing budget.

The possibilities for redistributing money in this way are, in principle, favoured by the unprecedentedly broad scope of Allègre's 'superministry', which has responsibility for virtually all aspects of education, science and technology.

Research organizations and universities are concerned, however, that the increase in recruitment could actually make matters worse unless it is accompanied by extra research funds, as salary costs already eat up most of the research agencies' budgets.

Salaries already account for 80 per cent of the budget of the Centre National de la Recherche Scientifique (CNRS), for example, and despite large staff cuts this proportion grew by 3 per cent last year, whereas the agency's total budget grew by just 1.5 per cent. An increase in recruitment would seriously exacerbate this situation, unless it were accompanied by a large increase in CNRS's overall funding, says Pierre Tambourin, director of the agency's life sciences division.

At the same time, the government plans to introduce a system of postdoctoral fellowships. It says this is needed to absorb the 10,000 to 15,000 unemployed postdoctoral researchers and to promote mobility, but that the ultimate aim is for postdoctoral researchers to find permanent jobs. To encourage recruitment in the private sector, it proposes increasing tax credits on research for small and medium-sized companies, while indexing these directly to specific recruitment targets.

Henri-Edouard Audier, a chemist at the Ecole Polytechnique and a member of the national bureau of the National Union of Scientific Researchers (SNCS), says that the unions accept the government's arguments

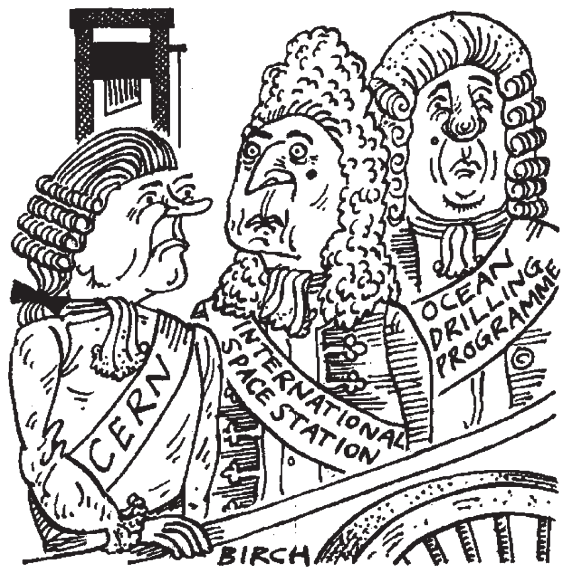

about the need for more flexibility as a provisional measure. But it does not want this to become a slippery slope towards the AngloSaxon system, with a large population of researchers on short-term contracts.

\section{Shake-up for CNRS}

The research organizations themselves face the prospect of radical shake-up. They have been asked to justify their activities, as well as to identify areas of duplication.

"We need to look at the entire research landscape from scratch," says Tambourin, arguing that a large institute for human pathologies could regroup the biomedical research agency INSERM and parts of CNRS, while a new agency dedicated to studies of the planet could regroup research on biodiversity, the environment and other areas.

Orstom, the agency for research in developing countries, seems almost certain to be abolished, for many now in power consider it to be an anachronism of colonialism, and as much an instrument of French foreign policy as a research agency. Its core activities are likely to be redistributed among the other agencies.

The unions have previously resisted the expected reforms in the allocation of jobs and money. But they are now making conciliatory noises. Audier concedes that the goals of the research organizations need to be redefined, and says this will be acceptable provided the changes are carried out in genuine consultation with all the parties involved.

Audier is optimistic that the national priority now being given to research has improved the climate for negotiating this and other reforms. But there has already been one major disagreement between the unions and the ministry. Allègre wants to reduce drastically the size of the research agency committees that evaluate laboratories and set scientific strategy, and in particular CNRS's powerful national committee, which consists of commissions covering 40 disciplines.

Declan Butler 